\title{
Conservative Management of Acoustic Neuroma
}

\author{
Abdulrahman Al Sanosi, M.D., ${ }^{1}$ Paul A. Fagan, M.D., F.R.C.S., F.R.A.C.S., ${ }^{2}$ \\ and Nigel D.W. Biggs, M.D., F.R.A.C.S. ${ }^{2}$
}

\section{ABSTRACT}

Aim of study: To identify those patients with vestibular schwannoma (acoustic neuroma) in whom treatment becomes necessary. Method: Retrospective chart review. Result: A total of 205 patients with small tumors were followed for a mean of 40.8 months. The longest follow-up was 180 months. One hundred and ninety-seven patients had a follow-up of more than 12 months. Eight patients with a follow-up of less than 12 months were excluded from the study. In 136 patients (66.3\%) the tumor did not grow. Forty-seven patients (23.9\%) showed some evidence of slow growth. Eight of 197 patients (4\%) had rapid growth and 6 patients (3\%) had radiological evidence of tumor regression. Fifteen patients came to surgery. Five of these showed rapid growth, four developed ataxia in whom tumor growth was slow, three had ataxia without tumor growth, two patients developed brainstem compression, and one patient elected to proceed to surgery, although there were no tumor growth or symptoms. Conclusion: Few patients with small tumors will come to surgery in the short term. Perhaps the majority of patients with such small tumors will not need surgery. Long-term follow-up studies of 20 years or more are required to be come more confident about the natural history of these tumors. This study continues.

KEYWORDS: Acoustic neuroma, cerebellopontine angle, magnetic resonance imaging, nonsurgical management

Acoustic neuroma (AN), more properly known as vestibular schwannoma $(\mathrm{VS}),{ }^{1}$ is a benign tumor arising from the eighth cranial nerve in the internal auditory canal (IAC) and cerebellopontine

\footnotetext{
${ }^{1}$ Department of Otolaryngology, King Abdulaziz University Hospital, Riyadh, Kingdom of Saudi Arabia; ${ }^{2}$ Department of Otolaryngology/Skull Base Surgery, St. Vincent Hospital, Darlinghurst, Sydney, Australia.

Address for correspondence and reprint requests: Paul A. Fagan, M.D., 352 Victoria S., Darlinghurst NSW 2010, Australia. E-mail: pfagan@pfagan.com.au.
}

Skull Base 2006;16:95-100. Copyright (C) 2006 by Thieme Medical Publishers, Inc., 333 Seventh Avenue, New York, NY 10001, USA. Tel: +1(212) 584-4662.

Received: September 1, 2005. Accepted after revision: October 9, 2005.

Published online: April 1, 2006.

DOI 10.1055/s-2006-934112. ISSN 1531-5010. 
angle (CPA). Before the development of modern imaging techniques, such tumors generally presented late.

The advent of magnetic resonance imaging (MRI) has led to the diagnosis of small and minimally symptomatic tumors, sometimes even as a chance finding. In recent years, watchful waiting with observation of tumor size by repeated MRI (the so-called "wait and scan" option) has become common. Such a policy, carried out for many years, will lead to a better understanding of the natural history of these tumors.

\section{MATERIAL AND METHODS}

A retrospective review of patients with small tumors was undertaken from the charts of the senior authors (P.A.F. and N.D.W.B.). Conservative management is considered when the tumor is small or when there are unfavorable patient factors, such as extreme age or serious illness.

Patients with neurofibromatosis type 2 (NFII), previous surgery, or radiation therapy were excluded.

The tumor location was judged to be intracanalicular or intracanalicular with CPA extension. No tumors were solely in the CPA.

The duration of follow-up (time from the first scan to the last scan) and the size of the tumor on first and last scans (the largest measured diameter) were recorded.

Although from a surgical point of view it is the CPA component that is most important, in this study, overall size (i.e., IAC + CPA) was measured. Tumor behavior was judged to be slowly growing (i.e., change $<2 \mathrm{~mm}$ from last MRI), rapidly growing ( $>2 \mathrm{~mm}$ from last $\mathrm{MRI})$, stable, or reducing.

Table 1 Age at Presentation

\begin{tabular}{ll}
\hline Mean & 60.84 years \\
Minimum & 26 years \\
Maximum & 89 years \\
\hline
\end{tabular}

Table 2 Sex Distribution

\begin{tabular}{lcc}
\hline Gender & Frequency & Percentage \\
\hline Male & 91 & 44.4 \\
Female & 114 & 55.6 \\
Total & 205 & 100.0 \\
\hline
\end{tabular}

\section{RESULTS}

\section{Study Group}

A total of 205 patients with a radiological diagnosis of AN were managed conservatively between 1989 and 2005. Eight patients with a follow-up of less than 12 months were excluded from the following analysis. One hundred ninety-seven patients have had a follow-up of more than 12 months. Patient ages are given in Table 1 , sex distribution in Table 2, and symptomatology in Table 3.

\section{Tumor Diameter}

In 130 patients $(63.4 \%)$, the tumor was confined to the IAC. In 75 (36.6\%), the tumor involved both the IAC and the CPA (Table 4). The mean diameter at diagnosis was about $8.7 \mathrm{~mm}$ (range, 2 to $20 \mathrm{~mm}$ ) and the mean diameter at last follow-up was about $11 \mathrm{~mm}$ (range, 3 to $27 \mathrm{~mm}$ ) (Table 5).

The study group was divided into 10 subgroups based on the duration of follow-up (12 to 184 months) (Table 6). In 136 patients (66.3\%) the

Table 3 Summary of Symptoms at Presentation

\begin{tabular}{lcc}
\hline Symptoms & Frequency & Percentage \\
\hline Hearing loss & 95 & 46.3 \\
Tinnitus & 11 & 5.4 \\
Vertigo & 14 & 6.8 \\
Hearing loss, tinnitus, vertigo & 4 & 2.0 \\
Asymptomatic & 14 & 6.8 \\
Hearing loss, vertigo & 34 & 16.6 \\
Hearing loss, tinnitus & 28 & 13.7 \\
Ataxia & 5 & 2.4 \\
Total & 205 & 100.0 \\
\hline
\end{tabular}


Table 4 Tumor Location

\begin{tabular}{lcc}
\hline Site & Frequency & Percentage \\
\hline IAC & 130 & 63.4 \\
CPA + IAC & 75 & 36.6 \\
Total & 205 & 100.0 \\
\hline
\end{tabular}

IAC, internal auditory canal; CPA, cerebellopontine angle.

Table 5 Size of Tumor at First and Last MRI

\begin{tabular}{lcc}
\hline & First $\mathbf{M R \mathbf { I }}$ & Last $\mathbf{M R \mathbf { I }}$ \\
\hline Mean & $8.79 \mathrm{~mm}$ & $10.90 \mathrm{~mm}$ \\
Minimum & $2 \mathrm{~mm}$ & $3 \mathrm{~mm}$ \\
Maximum & $20 \mathrm{~mm}$ & $27 \mathrm{~mm}$ \\
\hline
\end{tabular}

$\mathrm{MRI}$, magnetic resonance imaging.

tumor did not grow. Forty-seven patients (23.9\%) showed some evidence of slow growth. Eight of 197 patients (4.1\% had rapid growth and 6 patients $(3 \%)$ had radiological evidence of tumor regression (Table 7). The majority (179 patients, 90.9\%) had no change in their symptoms.

Table 6 Subclassification of Groups Based on Duration of Follow-Up

\begin{tabular}{llcc}
\hline Groups & Follow-Up in Months & Frequency & Percent \\
\hline 1 & 12 & 33 & 16.8 \\
2 & $13-24$ & 46 & 23.4 \\
3 & $25-36$ & 23 & 11.7 \\
4 & $37-48$ & 25 & 12.7 \\
5 & $49-60$ & 30 & 15.2 \\
6 & $61-72$ & 21 & 10.7 \\
7 & $73-84$ & 6 & 3.0 \\
8 & $85-96$ & 1 & .5 \\
9 & $97-108$ & 5 & 2.5 \\
10 & More than 109 & 7 & 3.6 \\
Total & & 197 & 100.0 \\
\hline
\end{tabular}

Table 7 Growth Patterns of Tumor during Follow-Up

\begin{tabular}{lcc}
\hline Pattern of Growth & Frequency & Percentage \\
\hline Growth & 47 & 23.9 \\
Stable & 136 & 69.0 \\
Rapid growth & 8 & 4.1 \\
Shrunk & 6 & 3.0 \\
Total & 197 & 100.0 \\
\hline
\end{tabular}

Table 8 Indications for Groups Who Underwent Surgical Intervention

\begin{tabular}{lc}
\hline Indications for Intervention & Number \\
\hline Rapid growth & 5 \\
Ataxia & 3 \\
Growth and ataxia & 4 \\
Brainstem compression & 2 \\
Patient decision & 1 \\
Total & 15 \\
\hline
\end{tabular}

Fifteen patients came to surgery, five because of rapid growth; four had slow tumor growth with ataxia and three developed incapacitating ataxia/ vertigo although no growth was detected. Two patients developed brainstem compression and one patient elected to proceed to surgery although there were no tumor growth or symptoms (Table 8).

\section{DISCUSSION}

Vestibular schwannomas tend to be slow-growing tumors. ${ }^{2-6}$ There are at least 26 published studies on the conservative management of AN. ${ }^{7-30}$ A metanalysis of 21 of these studies (1345 patients) covered the years 1989 to 2003 .

The average length of follow-up for all was 3.2 years, ranging from 2.2 to 5 years, ${ }^{31}$ but a much longer period of observation is desirable.

The methods of tumor measurement have varied widely, ${ }^{25,29,32-34}$ with some authors believing that volume assessment is essential. However, it is our opinion that tumor assessment should be much simpler.

In a word, a decision about intervention, whether by surgery or radiotherapy, should be made for two reasons only: because of the severity of symptoms, or because of incipient or actual brain stem compression. Any tumor of less than $1.5 \mathrm{~cm}$ in the CPA would be very unlikely to produce a brainstem problem, which provides a good rule of thumb when intervention is under consideration.

In this series, 15 patients came to surgery. Four patients showed some tumor growth but 
developed gross ataxia, 3 patients developed incapacitating ataxia/vertigo without tumor growth, 2 patients developed brainstem compression, and 1 patient elected to proceed to surgery although there was no tumor growth or new symptoms. Finally, 5 patients showed tumor growth without brainstem compression. It might be said that further conservative management of this last group could have been undertaken safely.

All of the patients (100\%) who came to surgery have normal facial function (House-Brackmen grade I) as do all the patients who did not have surgery.

This high a figure is rarely reported when more active intervention is undertaken.

All operated patients lost hearing. Of these 15 patients, 11 were judged to have useful hearing but only 3 were within $30 \mathrm{~dB}$ of the other ear, making the usefulness of such hearing a doubtful proposition according to the Belfast rule of thumb ${ }^{35}$ and the Glasgow Benefit plott. ${ }^{36}$

\section{CONCLUSION}

In general, small acoustic tumors neither grow nor produce major symptoms. Many current studies suggest that any treatment may prove to be unnecessary. Long-term studies, perhaps up to 20 years or more, are required to learn more about the natural history of these tumors.

\section{REFERENCES}

1. Lanser MJ, Sussman SA, Frazer K. Epidemiology, pathogensis, and genetics of acoustic tumors. Otolaryngol Clin North Am 1992;25:499-520

2. Nedzelski JM, Schessel DA, Pfleiderer A, Kassel EE, Rowed DW. Conservative management of acoustic neuromas. Otolaryngol Clin North Am 1992;25:691705

3. Silverstein H, McDaniel A, Norrell H, Wazen J. Conservative management of acoustic neuroma in the elderly patient. Laryngoscope 1985;95:766-770
4. Strasnick B, Glasscock ME 3rd, Haynes D, McMenomey $\mathrm{SD}$, Minor LB. The natural history of untreated acoustic neuromas. Laryngoscope 1994;104:1115-1119

5. Rosenberg SI, Silverstein H, Gordon MA, Flanzer JM, Willcox TO, Silverstein J. A comparison of growth rates of acoustic neuromas: non-surgical patients vs. subtotal resection. Otolaryngol Head Neck Surg 1993;109:482487

6. Wazen J, Silverstein H, Norrell H, Bessc B. Preoperative and postoperative growth rates in acoustic neuromas documented with CT scanning. Otolaryngol Head Neck Surg 1985;93:151-155

7. Silverstein H, Rosenberg SI, Flanzer JM, Wahamaker HH, Seidmen MD. An algorithm for the management of acoustic neuromas regarding age, hearing, tumor size, and symptoms. Otolaryngol Head Neck Surg 1993;180:1-10

8. Nedzelski JM, Canter RJ, Kassel EE, Rowed DW, Tator $\mathrm{CH}$. Is no treatment good treatment in the management of acoustic neuromas in the elderly? Laryngoscope 1986;96: 825-829

9. Nedzelski JM, Schessel DA, Pfleiderer A, Kassel EE, Rowed DW. Conservative management of acoustic neuromas. Otolaryngol Clin North Am 1992;25:691-705

10. Jørgensen BG, Pedersen CB. Acoustic neuroma. Followup of 78 patients. Clin Otolaryngol Allied Sci 1994;19: 478-484

11. Martin C, Martin H, Portafaix M, Saby JL. De la particulière lenteur d'évolution de certains neurinomes de l'acoustique [peculiarly slow development of several acoustic neuromas. Management.]. Ann Otolaryngol (Chir Cervicofac) 1985;102:19-29

12. Wazen J, Silverstein H, Norrell H, Besse B. Preoperative and postoperative growth rates in acoustic neuromas documented with CT scanning. Otolaryngol Head Neck Surg 1985;93:151-155

13. Clark WC, Moretz WH Jr, Acker JD, Gardner LG, Eggers F, Robertson JH. Nonsurgical management of small and intracanalicular acoustic tumors. Neurosurgery 1985; 16:801-803

14. Laasonen EM, Troupp H. Volume growth rate of acoustic neurinomas. Neuroradiology 1986;28:203-207

15. Gardner G, Moretz WH Jr, Robertson JH, Clark C, Shea JJ Jr. Nonsurgical management of small and intracanalicular acoustic tumors. Otolaryngol Head Neck Surg 1986;94: 328-333

16. Kassel EE, Nedzelski JM, Canter RJ, Rowed DW, Cooper PW. Radiologic assessment of acoustic neuroma in the elderly. Is no treatment good treatment? Acta Radiol Suppl 1986;369:182-185

17. Thomsen J, Tos M. Acoustic neuromas. Diagnostic delay, growth rate and possible non-surgical treatment. Acta Otolaryngol Suppl 1988;452:26-33

18. Valvassori GE, Guzman M. Growth rate of acoustic neuromas. Am J Otol 1989;10:174-176

19. Wiet RJ, Young NM, Monsell EM, O'Connor CA, Kazan R. Age considerations in acoustic neuroma surgery: the horns of a dilemma. Am J Otol 1989;10:177-180 
20. Thomsen J, Tos M. Acoustic neuroma: clinical aspects, audiovestibular assessment, diagnostic delay, and growth rate. Am J Otol 1990;11:12-19

21. Bederson JB, von Ammon K, Wichmann WW, Yasargil MG. Conservative treatment of patients with acoustic tumors. Neurosurgery 1991;28:646-650

22. Anand VT, Kerr AG, Byrnes DP, Smyth GD. Nonsurgical management of acoustic neuromas. Clin Otolaryngol Allied Sci 1992;17:406-410

23. Strasnick B, Glasscock ME 3rd, Haynes D, McMenomey SO, Minor LB. The natural history of untreated acoustic neuromas. Laryngoscope 1994;104:1115-1119

24. Wiet RJ, Zappia JJ, Hecht CS, O'Connor CA. Conservative management of patients with small acoustic tumors. Laryngoscope 1995;105:795-800

25. Charabi S, Thomsen J, Mantoni M, et al. Acoustic neuroma (vestibular schwannoma): growth and surgical and nonsurgical consequences of the wait-and-see policy. Otolaryngol Head Neck Surg 1995;113:5-14

26. Deen HG, Ebersold MJ, Harner SG, et al. Conservative management of acoustic neuroma: an outcome study. Neurosurgery 1996;39:260-264; discussion 264-266

27. Levo H, Pyykkö I, Blomstedt G. Non-surgical treatment of vestibular schwannoma patients. Acta Otolaryngol Suppl 1997;529:56-58

28. Yamamoto M, Hagiwara S, Ide M, et al. Conservative management of acoustic neurinomas: prospective study of long-term changes in tumor volume and auditory function. Minim Invasive Neurosurg 1998;41:86-92

29. Niemczyk K, Vaneecloo FM, Lemaitre L, et al. The growth of acoustic neuromas in volumetric radiologic assessment. Am J, Otol 1999;20:244-248

30. Mirz F, Jørgensen B, Fiirgaard B, Lundorf E, Pedersen $\mathrm{CB}$. Investigations into the natural history of vestibular schwannomas. Clin Otolaryngol Allied Sci 1999;24:13-18

31. Smouha EE, Yoo M, Mohr K, Davis RP. Conservative management of acoustic neuroma: a meta-analysis and proposed treatment algorithm. Laryngoscope 2005;115: 450-454

32. Long SA, Arriaga M, Nelson RA. Acoustic neuroma volume: MRI-based calculations and clinical implications. Laryngoscope 1993;103:1093-1096

33. Fiirgaard B, Pedersen CB, Lundorf E. The size of acoustic neuromas: CT and MRI. Neuroradiology 1997;39:599-601

34. Monsell EM, Cody DD, Spickler E, Windham UP. Segmentation of acoustic neuromas with magnetic resonance imaging and Eigen image filtering. Am J Otol 1997; 18:602-607

35. Toner JG, Smyth GD. Comparison of methods of evaluating benefit of middle ear surgery. J Laryngol Otol 1993;107:4-5

36. Browning GG, Gatehouse S, Swan IR. The Glasgow Benefit Plot: a new method for reporting benefits from middle ear surgery. Laryngoscope 1991;101:180-185 
